\title{
Organizational Wellbeing among Workers in Mental Health Services: A Pilot Study
}

\author{
Federica Sancassiani $^{1, *}$, Marcello Campagna ${ }^{1}$, Francesco Tuligi $^{2}$, Sergio Machado $^{3,4}$, Elisa Cantone ${ }^{1}$ \\ and Mauro Giovanni Carta ${ }^{1}$
} ${ }^{I}$ Department of Public Health, Clinic and Molecular Medicine - University of Cagliari, Italy; ${ }^{2}$ Department of Mental
Health - Local Health Unit of Lanusei, Italy; ${ }^{3}$ Institute of Psychiatry of Federal University of Rio de Janeiro, Brazil;
${ }^{4}$ National Institute for Translational Medicine (INCT-TM), Brazil

\begin{abstract}
Introduction: Organizational wellbeing in mental health services influences the outcomes of users and their families. Workers should be motivated, have a positive morale and be able to recognize values and the deep meaning of their work. This survey aims to examine the organizational wellbeing of the services provided by the Department of Mental Health (DSM) in Lanusei (Italy) and the correlations between job satisfaction and the psychosomatic health of its workers. Materials and Methodology: Descriptive-correlational study on a population of 43 mental health workers. Organizational wellbeing, as well as workers' job satisfaction and psychosomatic health, were measured using the "Multidimensional Organizational Health Questionnaire" (MOHQ). It is a self-report questionnaire able to examine 14 dimensions of organizational wellbeing, 14 indicators about individual discomfort, 12 indicators about individual wellbeing, 8 psychosomatic symptoms related to job distress. Results: 31 workers $(72 \%)$ participated in the survey. Regarding the organizational wellbeing of DSM, the general profile mean \pm sd was $2.66 \pm 0.28$ (values from 1 to $4: 1=$ never, $4=$ often). Job satisfaction was negatively correlated with headaches and concentration difficulties $(\mathrm{R}=-.584, \mathrm{p}=0.001)$, nervousness, restlessness, anxiety $(\mathrm{R}=-.571, \mathrm{p}=0.001)$, sense of excessive fatigue $(\mathrm{R}=-.634, \mathrm{p}=0.000)$ and sense of depression $(\mathrm{R}=-.558$, $\mathrm{p}=0.001$ ) reported by workers. Conclusions: Data denoted an overall healthy state of the DSM. There were significant correlations between workers' job satisfaction and their psychosomatic health. The recognition and restitution about the weakness and strengths of the services could be useful to point out some organizational development perspectives.
\end{abstract}

Keywords: Job satisfaction, mental health services, organizational wellbeing.

\section{INTRODUCTION}

Job satisfaction and work engagement of workers are important dimensions for the quality of community mental health services [1-5]. They are associated with high levels of energy, enthusiasm and positive morale at work $[1,4,5]$, are at the opposite end of burnout on core factors describing the work experience $[1,4,5]$, lead to more favourable patient outcomes [3] and produce mutual influences with other dimensions of organizational wellbeing [6].

In the mental health care setting these relations are nourished by the nature of the tasks provided, strongly marked by the therapeutic relationship between workers and users $[1,3,7]$. The centrality of users and the humanization of care involve many abilieties of the workers, such as listening, continuity in caring, timeliness, good skills in communication, problem solving and crisis management. Furthermore, in Italy as well as in other European countries with a National Public Health System, mental health services are facing severe financial shortages and consequent shortfalls in the number of sector-employed professionals [8-11]. Even more, the quality of the performances depends

*Address correspondence to this author at the Department of Public Health, Clinical and Molecular Medicine, University of Cagliari, Italy; Tel/Fax: 00390706093498;

E-mail: federicasancassiani@yahoo.it also on the professional and personal qualities of workers, who often offset structural deficiencies and procedural difficulties with their efforts and highly skilled job. This remarkable workload, together with other individual and organizational factors, could expose individuals who work in the mental health field to an high risk of job-related distress and burnout [12-17].

On the other hand, working in mental health care provides a wide range of experiences, relationships and encounters that are not only characterised by the risk of frustration and disappointment, but also by joy, fascination and satisfaction [1]. The people who work in mental health services should be competent and motivated, be able to recognize the values and deep meaning of their work, be aware of the centrality and importance of their role in promoting wellbeing among users and into their work place $[1,18,19]$.

Organizational wellbeing could be defined as "the whole of cultural, processes and organizational practices that light up co-working life, promoting, maintaining and improving the physical, psychological and social wellbeing of work communities" [6, 19-21].

The examination of organizational wellbeing is often the first step of an organizational development process. A critical and participated recognition of the social climate at work, the psychosocial risk and protective factors for a good 
quality of working life and job satisfaction could be useful both to improve workers' functionality and wellbeing, and to point out some perspectives of organizational development $[6,19,20-24]$.

Our study examines the organizational wellbeing of a public community centered mental health care department in Lanusei, Italy, in order to point out psychosocial protective and risk factors related to job distress and organizational development perspectives.

We also tested the correlations between job satisfaction and psychosomatic symptoms reported by workers, in order to underline the relevance of workers' health for their work engagement.

\section{MATERIALS AND METHODOLOGY}

\section{Design}

Descriptive-correlational study on a population of mental health workers.

\section{Sample and Setting}

As shown in Table 1, the study population included all the 43 mental health workers of the mental health services under the Department of Mental Health (DSM) of Lanusei, Italy.

The Italian public mental health care system is as wellknown community centre built without mental hospital. In the Sardinian region it is organized on the basis of eight similar sector areas ("Dipartimenti di Salute Mentale DSM"), corresponding to the eight administrative areas ("Province"). Each administrative area is divided into community catchment areas ("Centri di Salute Mentale - CSM"), serving a target adult population between 50.000 and 150.000 inhabitants. The DSM of Lanusei is the smallest one in Sardinia, with only one CSM covering around 60.000 adults inhabitants.

\section{Instruments}

Organizational wellbeing was measured using the "Multidimensional Organizational Health Questionnaire MOHQ", a self-report questionnaire validated among 3197 employees of the Italian Public Administration [6]. It is used to examine 14 dimensions of organizational wellbeing and their domains: "Clearness about goals" (4 items), "Skills enhancement" (4 items), "Active listening" (4 items), "Availability of information" (4 items), "Conflict management" (4 items), "Collaborative interpersonal relationships" (4 item), "Workability" (4 items), "Distress" (4 items), "Social utility" (4 items), "Fairness" (4 items), "Comfort" (8 items), "Job demands" (10 items), "Safety" (8 items), "Openness to innovation" (9 items). MOHQ also evaluates a list of 14 indicators about individual discomfort and a list of 12 indicators about individual wellbeing in the organization. Finally, it examines a list of 8 psychosomatic symptoms related to job distress. Cronbach's alpha coefficients of each dimension scored between 0.60 and 0.91 (mean=0.76; $\mathrm{sd}=0.10$ ) [6].

The lists of indicators about individual discomfort and individual wellbeing in the organization, taken as a whole, can be considered a measure of job satisfaction [6].
Each item of the questionnaire is scored from 1 to 4 , ranging from $1=$ never to $4=$ often. A high score corresponds to a positive assessment of the single dimension, excepting: "Conflict management", "Distress", "Job demands", "Indicators about individual discomfort", "Psychosomatic symptoms". A high score in the latter, because of their semantic reversed polarity, is related to a negative evaluation. For this reason during data processing, the scores in those dimensions had to be reversed $(1=4,2=3,3=2,4=1)$ in order to achieve a uniform criterion: a high score corresponds to a positive evaluation of each dimension.

The overall mean from the scores distribution obtained in all dimensions is the numeric value used to discuss the general health profile of the organization. Therefore, higher scores than the overall mean match the strengths of the organization, lower scores than the overall mean correspond to their weak points. The approximate cut-off scores for the overall mean, identified by the MOHQ manual, are: $>2.9=$ healthy organization; between 2.6 and 2.9 = intermediate; < $2.6=$ unhealthy organization [6].

Moreover, socio-demographic and other work related variables were assessed by an "anagraphic" session of the MOHQ.

\section{Procedure}

The study was promoted under the project "QAL.SAR.PSY." [8, 10], as a part related to the quality of the working life of workers in Sardinian mental health services specifically.

The main aims and the procedure of the study were defined during a meeting with the manager of the DSM of Lanusei and a small group of workers.

We collected data by MOHQ in a group session, where each worker completed the questionnaire individually and anonymously.

After data processing, we drew up a data report to discuss the results with the participants and the manager of the DSM of Lanusei in order to point out prospective areas of organizational development.

\section{Statistical Analysis}

Statistical analysis was conducted using SPSS 16.

To describe socio-demographic and work-related variables of the sample (age; gender; marital status; education; professional status; number of workers/type of mental health service; working time; past employment), we conducted a series of descriptive analyses (frequencies and percentages).

To describe the general health profile of the DSM of Lanusei we calculated the overall mean (and standard deviation) about: the 14 dimensions of organizational wellbeing; the 14 indicators about individual discomfort; the 12 indicators about individual wellbeing; and the 8 psychosomatic symptoms related to job distress.

To describe psychosocial protective and risk factors about work-related distress in the organization, we calculated the means and deviations from the overall mean of the general profile for each dimension of the organizational health, 
the list of indicators about individual discomfort, the list of indicators about individual wellbeing and the list of psychosomatic symptoms. Therefore, higher scores than the overall mean match the strengths of the organization, lower scores than the overall mean correspond to their weak points.

We calculated the means and standard deviations for both individual discomfort and individual wellbeing in the organization, taken as a whole, in order to obtain a measure of job satisfaction. Finally, we used Pearson correlations to test the correlations between job satisfaction and the psychosomatic symptoms reported by workers.

\section{Ethical Aspects}

Each subject in the study was identified with a code number not ascribable to their name by researchers. Informed consent for the use of anonymous data for scientific purposes was obtained from each participant. This study was approved by the Ethics Committee of the Cagliari University Hospital "Azienda Mista Ospedaliero-Universitaria di Cagliari".

\section{RESULTS}

\section{Socio-Demographic and Work-Related Characteristics of the Sample}

Among the 43 workers of the DSM of Lanusei, 31 (72\%) took part in the study. The others declined the participation to the survey.

Comparing the workers who participated in the study to those who did not, we did not find statistically significant differences regarding gender, age or mental health service of provenance.

The socio-demographic and work-related characteristics of the sample are illustrated in Table $\mathbf{1 .}$

\section{General Wellbeing Profile of the Organization}

As shown in Fig. (1), the overall mean describing the general health of the DSM is $2.66(\mathrm{sd}=0.28)$.

Table 2 pointed out psychosocial protective and risk factors about work-related distress in the DSM. The dimensions that reached a higher mean score than the overall mean of the general health profile of the organization match the strengths of the organization. They were: "Social utility" (mean $\pm \mathrm{sd}=3.11 \pm 0.35)$, "Active listening" (mean $\pm \mathrm{sd}=$ $3.10 \pm 0.25)$, "Psychosomatic symptoms" (mean $\pm \mathrm{sd}=2.98$ \pm 0.39 ), "Collaborative interpersonal relationship" (mean \pm $\mathrm{sd}=2.98 \pm 0.15)$, "Availability of information" (mean $\pm \mathrm{sd}=$ $2.86 \pm 0.06)$, "Workability" (mean $\pm \mathrm{sd}=2.81 \pm 0.15)$, "Individual wellbeing in the organization" (mean $\pm \mathrm{sd}=2.79 \pm$ 0.20).

The dimensions that reached a lower mean score than the overall mean of the general health profile match the weak points of the organization. They were: "Fairness" (mean $\pm \mathrm{sd}$ $=2.12 \pm 0.57)$, "Distress" (mean \pm sd $=2.30 \pm 0.31$ ), "Job demands" (mean $\pm \mathrm{sd}=2.41 \pm 0.49)$, "Openness to innovation" (mean $\pm \mathrm{sd}=2.44 \pm 0.32$ ), "Skills enhancement" (mean $\pm \mathrm{sd}=2.48 \pm 0.55)$, "Safety" (mean $\pm \mathrm{sd}=2.52 \pm 0.35)$, "Individual discomfort in the organization" (mean $\pm \mathrm{sd}=2.54 \pm$ $0.25)$.
Table 1. Characteristics of the sample.

\begin{tabular}{|l|l|}
\hline Variable & Descriptive Statistics \\
\hline \hline N (\%) sample & $\mathrm{N}=43(100 \%)$ \\
\hline Collected questionnaires & $\mathrm{N}=31(72 \%)$ \\
\hline Professional status & \\
Psychiatrist & $\mathrm{N}=7(23 \%)$ \\
Psychologist - Psychotherapist & $\mathrm{N}=4(13 \%)$ \\
Nurse & $\mathrm{N}=11(35 \%)$ \\
Educator & $\mathrm{N}=6(19 \%)$ \\
Social worker & $\mathrm{N}=3(10 \%)$ \\
\hline Number of workers/type of mental health & \\
service & \\
mental health service for substances & \\
dipendence (Ser-d) & $\mathrm{N}=5(16 \%)$ workers \\
community mental health center (CSM) & $\mathrm{N}=19(61 \%)$ workers \\
residencial mental health provider & $\mathrm{N}=7(23 \%)$ workers \\
\hline Gender & \\
female & $\mathrm{N}=24(78 \%)$ \\
male & $\mathrm{N}=5(16 \%)$ \\
not reported & $\mathrm{N}=2(6 \%)$ \\
\hline Age & \\
>45 years old & $\mathrm{N}=21(68 \%)$ \\
31-45 years old & $\mathrm{N}=4(13 \%)$ \\
<30 anni & $\mathrm{N}=3(10 \%)$ \\
\hline not reported & $\mathrm{N}=6(19 \%)$ \\
\hline Education & $\mathrm{N}=1(3 \%)$ \\
8 years & $\mathrm{N}=3(10 \%)$ \\
13 years & \\
16 years & $\mathrm{N}=2(6 \%)$ \\
not reported & $\mathrm{N}=12(40 \%)$ \\
\hline Marital status & $\mathrm{N}=3(10 \%)$ \\
unmarried & $\mathrm{N}=11(35 \%)$ \\
married & $\mathrm{N}=3(10 \%)$ \\
separated/divorced & \\
not reported & $\mathrm{N}=5(10 \%)$ \\
\hline Work shift & $\mathrm{N}=21(70 \%)$ \\
full-time (36 hours/week) & $\mathrm{N}=1(3 \%)$ \\
part-time (18 hours/week) & \\
not reported & \\
\hline Past employing & \\
Not reported & \\
\hline
\end{tabular}

\section{Job Satisfaction and Psychosomatic Symptoms}

Table 3 shows the mean score about job satisfaction, obtained by joining the domains of individual discomfort and individual wellbeing in the organization. Table 4 shows Pearson correlations between job satisfaction and psychosomatics symptoms reported by workers. There were negative correlations between job satisfaction and: "headaches and concentration difficulties" $(\mathrm{R}=-.584, \mathrm{p}=0.001)$; "nervousness, restlessness, anxiety" ( $\mathrm{R}=-.571, \mathrm{p}=0.001)$; "sense of excessive fatigue" $(\mathrm{R}=-.634, \mathrm{p}=0.000)$; "sense of depression" ( $\mathrm{R}=-.558, \mathrm{p}=0.001)$, respectively. 


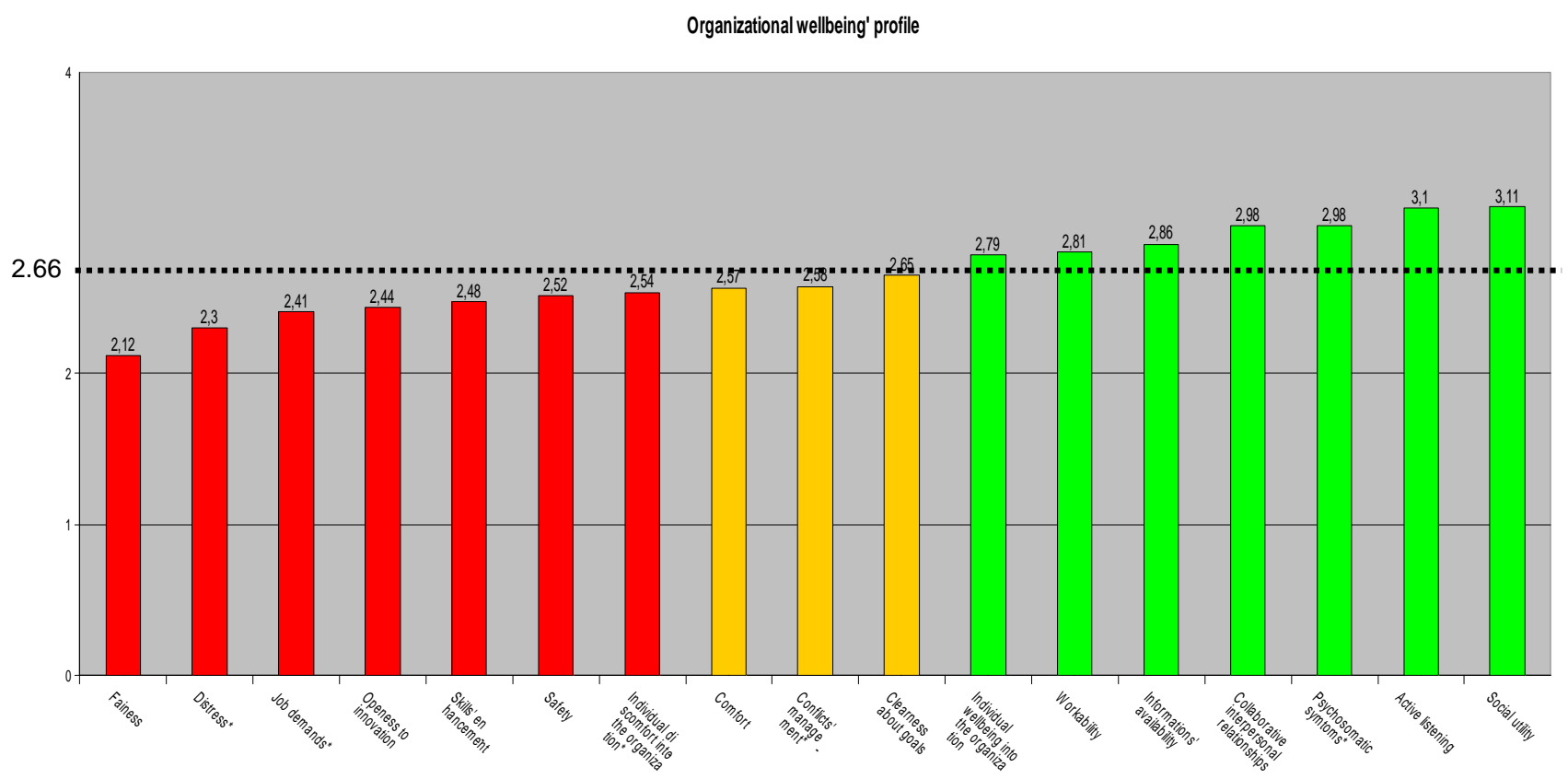

Fig. (1). Organizational wellbeing' profile of DSM (overall mean = 2.66).

Table 2. Weak points and strenghts of the DSM of lanusei.

\begin{tabular}{|c|c|c|c|c|}
\hline $\begin{array}{c}\text { Organizational } \\
\text { wellbeing' dimensions }\end{array}$ & Mean (sd) & $\begin{array}{c}\text { Overall } \\
\text { mean }\end{array}$ & $\begin{array}{c}\text { Deviation from } \\
\text { overall mean }\end{array}$ & Weak points/Strengths \\
\hline Fairness & $2.12(0.57)$ & 2.66 & -0.54 & Weak point \\
\hline Ditress* & $2.30(0.31)$ & 2.66 & -0.36 & Weak point \\
\hline Job demands* & $2.41(0.49)$ & 2.66 & -0.25 & Weak point \\
\hline Skills' enhancement & $2.48(0.55)$ & 2.66 & -0.18 & Weak point \\
\hline Safety & $2.52(0.35)$ & 2.66 & -0.14 & Weak point \\
\hline Individual discomfort into the organization* & $2.54(0.25)$ & 2.66 & -0.12 & Weak point \\
\hline Clearness about goals & $2.65(0.12)$ & 2.66 & -0.01 & intermediate \\
\hline Individual wellbeing into the organization & $2.79(0.20)$ & 2.66 & 0.13 & strenght \\
\hline Workability & $2.81(0.15)$ & 2.66 & 0.15 & strenght \\
\hline Informations' availability & $2.86(0.06)$ & 2.66 & 0.20 & strenght \\
\hline Collaborative interpersonal relationships & $2.98(0.15)$ & 2.66 & 0.32 & strenght \\
\hline Psychosomatic symtoms* & $2.98(0.39)$ & 2.66 & 0.32 & strenght \\
\hline Active listening & $3.10(0.25)$ & 2.66 & 0.44 & strenght \\
\hline
\end{tabular}

* Scores reversed $(1=4,2=3,3=2,4=1)$ for the asterisked dimensions 
Table 3. Job Satisfaction' domains and mean (sd) score.

\begin{tabular}{|c|c|c|}
\hline & ITEM (domains) & \\
\hline \multirow{12}{*}{$\begin{array}{l}\text { Individual } \\
\text { wellbeing into } \\
\text { the organization }\end{array}$} & $\begin{array}{l}\text { General satisfaction with the work } \\
\text { of the organization }\end{array}$ & \multirow{26}{*}{$\begin{array}{c}\text { Job } \\
\text { Satisfaction } \\
\text { Mean }=2.63 \\
(0.59) \\
\mathrm{N}=31\end{array}$} \\
\hline & $\begin{array}{l}\text { Pleasure to commit new energies to } \\
\text { the organization }\end{array}$ & \\
\hline & feeling of being part of a team & \\
\hline & Pleasure to go to work & \\
\hline & $\begin{array}{l}\text { feeling of personal fulfillment by } \\
\text { working }\end{array}$ & \\
\hline & $\begin{array}{l}\text { trust in actual negative conditions' } \\
\text { change }\end{array}$ & \\
\hline & $\begin{array}{c}\text { Sense of good balance between } \\
\text { work and leisure time }\end{array}$ & \\
\hline & $\begin{array}{l}\text { Satisfation for the quality of the } \\
\text { relationships estabilised at work }\end{array}$ & \\
\hline & $\begin{array}{c}\text { Sharing the work and values of the } \\
\text { organization }\end{array}$ & \\
\hline & $\begin{array}{l}\text { Agreement with actions and values } \\
\text { of the organization }\end{array}$ & \\
\hline & $\begin{array}{l}\text { appreciating human and moral } \\
\text { qualities of managers }\end{array}$ & \\
\hline & $\begin{array}{l}\text { Perceiving that the organization's } \\
\text { work is appreciated by outside }\end{array}$ & \\
\hline \multirow{14}{*}{$\begin{array}{l}\text { Individual } \\
\text { discomfort } \\
\text { into the organi- } \\
\text { zation* }\end{array}$} & Intolerance about going to work & \\
\hline & Lack of interest about work & \\
\hline & Desire to change job & \\
\hline & Gossip & \\
\hline & $\begin{array}{l}\text { Resentment towards the } \\
\text { organization }\end{array}$ & \\
\hline & Aggressiveness and nervousness & \\
\hline & Feeling of carry out useless work & \\
\hline & $\begin{array}{l}\text { Feeling to matter little into } \\
\text { organization }\end{array}$ & \\
\hline & $\begin{array}{l}\text { Feeling of not being adequately } \\
\text { evaluated }\end{array}$ & \\
\hline & $\begin{array}{l}\text { Feeling of working mechanically, } \\
\text { without involvement }\end{array}$ & \\
\hline & Slow execution of the tasks & \\
\hline & $\begin{array}{l}\text { Lack of clearness on "what needs } \\
\text { to be done and who should do it" }\end{array}$ & \\
\hline & Lack of ideas, lack of initiative & \\
\hline & $\begin{array}{l}\text { Over the past six months, how long } \\
\text { you been absent from work } \\
\text { (excluding public holidays)? }\end{array}$ & \\
\hline
\end{tabular}

* Scores reversed $(1=4,2=3,3=2,4=1)$

\section{DISCUSSION}

This study focused on the subjective evaluation of organizational wellbeing performed by the workers of the community mental health care services managed under the DSM of Lanusei in Italy.

Workers' subjective evaluation of organizational wellbeing could be a useful step to assess job-related distress into the organizations, especially about the "job content" and "job context" indicators (EU-OSHA, 2000) [24]. Therefore, it could be useful to promote a critical and participated recognition about the organizational climate and to point out perspectives for organizational development $[6,19,20,21]$. For this reason, a report concerning the main weak points and strengths of the organization was submitted and it was discussed with the manager of the DSM of Lanusei.

The following issues are extracted from the report about the DSM of Lanusei and they may provide some generalizable knowledge relevant to other mental health services.

\section{Organizational Health in the DSM of Lanusei: Main Weaknesses}

The mean score of the general profile, as well as the scores about the domains in each organizational wellbeing dimension, denoted an overall healthy state of the organization [6]. Some dimensions were considered as psychosocial risk factors for work-related distress.

"Fairness" emerged as the worst aspect in the organization. This result is consistent with studies carried out with other Italian public services [6, 21, 22]. As suggested by the low scores on domains such as "Bonus assignment is based on the effectiveness of the performance", "Organization provides career opportunities to everyone", and "Workers are evaluated by fair and transparent criteria", poor fairness was mainly related to incentive and career development systems, which are not based enough on meritocratic criteria.

On the other hand, workers perceived that "Managers treat employees fairly". Thus, poor fairness was not attributed so much to the dynamics of hierarchy within the organization, but rather to the wider context of the "healthcare political system" (i.e.: workers and managers vs. the Local Health Unit, vs. the health policies of the Region of Sardinia, and so on).

"Distress" and "Job demands" were expressed as critical dimensions and seemed to be closely connected to each other. Workers reported that "Work takes up energies completely" and "Tasks demand excessive stress and fatigue". Thus, coherently with the mental health service mandate, workers seemed to continuously exploit their relational skills, drawing into strong emotional investments and excessive fatigue. The critical domains of "Job demands", such as "Frequent contacts with other people", "Mental fatigue", "Direct responsibility about work", "Work overload", "Emotional overload" would account for the perceived distress. 
Table 4. Correlations between "job satisfaction" and "psychosomatic symptoms".

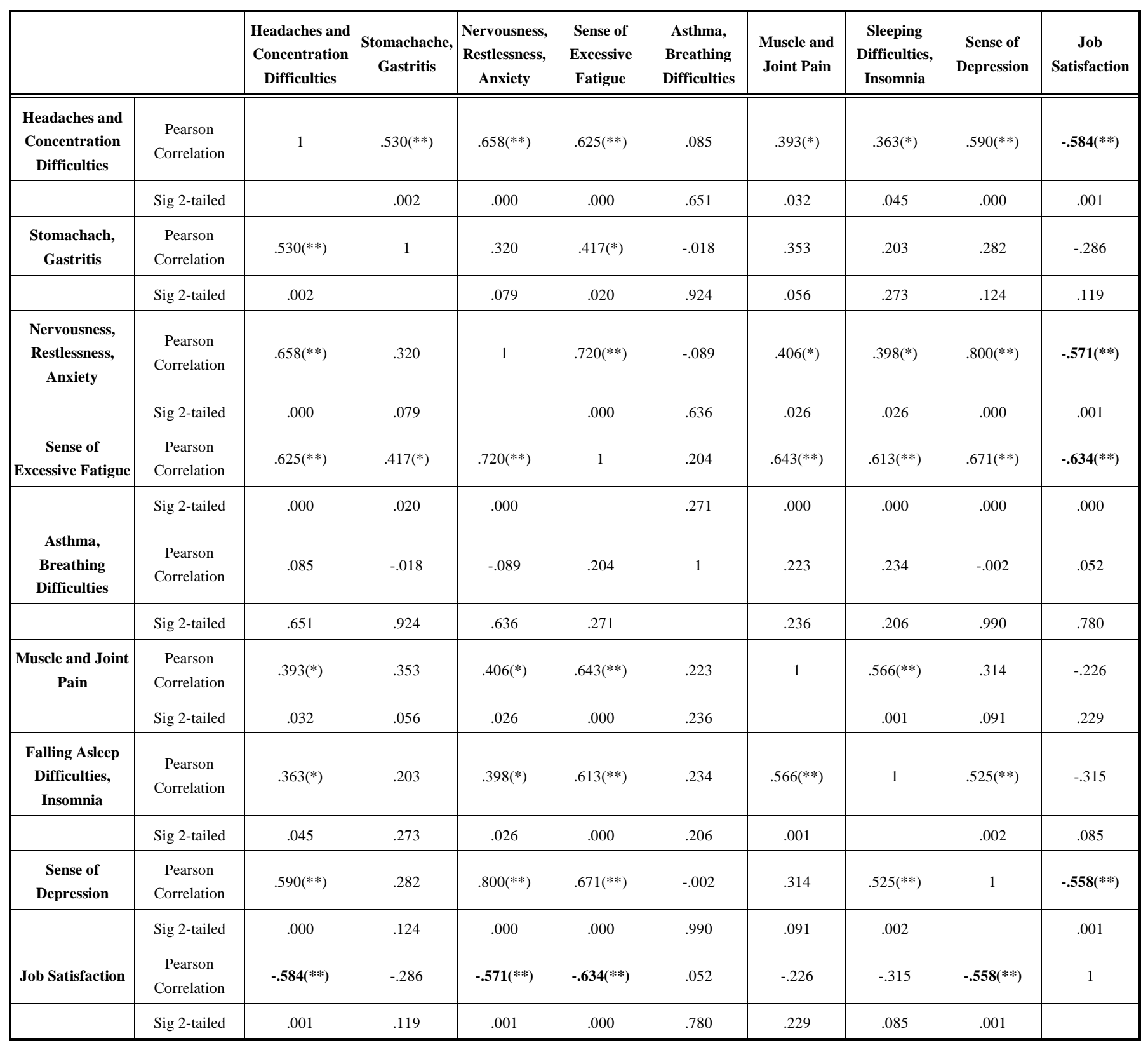

** Correlation is significant at the 0.01 level (2-tailed).

* Correlation is significant at the 0.05 level (2-tailed).

Another critical issue in the DSM of Lanusei was "Openness to Innovation", "Satisfying customers/users' requests" was the only positive domain in this dimension. This finding is consistent with the main aim of these services: improving users' health. However, openness to users as "health requestholders" could involve difficult caring if the organization was poorly open to "Acquire new technologies", "Develop innovative skills in employees", "Introduce new skills", "Deal with new forms of work organization", "Recognize and address past problems and mistakes", "Establish collaborative relationships with other organizations", "Improve work processes". These data seem to confirm the high scores in the previously-analyzed dimensions of "Distress" and "Job demands".
These problems highlight the need for organizational development perspectives, such as training and/or communication plans, changes in rules and procedures, intervention plans for the work organization.

\section{Organizational Health in the DSM of Lanusei: Main Strengths}

"Social utility" usually connotes the mission of a mental health service. In the DSM of Lanusei "Social utility" was a strength of the organization, especially the domain "Work of each employee represents a significant contribution", which pointed out operators' mutual recognition of the relevance of their work. Other domains receiving a positive evaluation in this dimension were "Organization provides useful services 
to the community" and "At the end of the working day you feel satisfied". These aspects are important motivating factors that could revitalize the organizational climate and the relationship dynamics of the working groups.

The domain "Are you satisfied of the organization's achievements" reached a lower score than the overall mean, maybe because of the operators' need for positive feedbacks from the outside.

The organizational dimensions "Active listening" and "Collaborative interpersonal relationships" reached high scores and are also typically promoted among users of mental health services. These data pointed out the coherence between the "how to be" of the organization, and its "knowhow". Therefore, it is extremely positive that both dimensions obtained high scores in these domains: "Operators are generally ready to meet the needs of the organization", "Manager wants to be informed about problems and difficulties related to work", "There is a collaboration among colleagues", "Managers involve operators in decisions affecting their work", "In working group, everyone is committed to achieve the results", "Working groups communicate with each other", "Those who make some requests or raise some proposals will be heard by the manager", "Colleagues give heed to and try to meet each other's needs".

\section{Correlations between job Satisfaction and Psychosomatic Symptoms}

As indicated by the authors of MOHQ [6], the list of indicators about individual discomfort and wellbeing in the organization can be considered as a whole measure of job satisfaction. The mean score on this dimension (2.63) was very near, but lower, than the mean score of the general profile (2.66). This result reflects the high and low scores reported by operators in the list of indicators about individual wellbeing and in the list of indicators about individual discomfort, respectively.

In the DSM of Lanusei, operators' wellbeing in the organization has been expressed by high scores in the domains: "Pleasure to go to work", "Pleasure to commit new energies to the organization", "Satisfaction for the quality of the relationships established at work", "Feeling of being part of a team"; "Agreement with actions and values of the organization"; "Sense of good balance between work and leisure time"; "Trust in professional skills of manager"; "Appreciating moral and human qualities of manager"; "General satisfaction with the work of the organization".

The only one domain that scored lower (2.42) than the general profile mean score was "Perceiving that the organization's work is appreciated outside". This result is consistent with the results obtained in the critical domains "Openness to Innovation" and "Active Listening", as previously discussed. In the list of the individual indicators of wellbeing in the organization the need for positive recognition from the outside was expressed. In the specific case of mental health services, the "outside" can be appropriately represented by both the users and the context where the services are located. This observation would open up a whole range of opportunities for the organization to enhance the visibility of its work. Territorial promotion initiatives sponsored by the DSM could be useful, for example, to consolidate the territorial area around mental health services and revitalize the quality of its relationships with the users.

The list of individual discomfort in the organization obtained negative evaluation in "Lack of clearness about what needs to be done and who should do it", thus pointing out a bad definition of roles and functions, and increasing excessive workload perception.

"Feeling of not being adequately evaluated", referred also to the "Fairness" and "Skills enhancement" dimensions, could reflect high scores obtained in the domains: "Resentment towards the organization", "Intolerance about going to work", "Lack of ideas and initiative", and "Desire to change job".

Another interesting result was the low score in the domain "Lack of interest about work", which reflected an overall positive implication and commitment, and the need for a fair evaluation that would recognize and appreciate individual qualities and skills within the organization as well.

"Psychosomatic symptoms" scores reflected the general healthy state of the DSM of Lanusei. The only one high score was "Sense of excessive fatigue". This index was coherent with the critical scores reported for "Distress" and "Tasks demand". As a source of psycho-physical discomfort, the sense of excessive fatigue was negatively correlated with job satisfaction. This means that the operators who perceived a high sense of excessive fatigue were not satisfied with the organization, and viceversa.

Among the list of "Psychosomatic symptoms", physical symptoms such as "stomachache, gastritis"; "asthma, breathing difficulties", "muscle and joint pain", "falling asleep difficulties, insomnia" did not correlate with job satisfaction. The symptoms concerning the mental health of workers and negatively correlated with job satisfaction were: "nervousness, restlessness, anxiety"; "headaches and concentration difficulties", and "sense of depression".

This result is coherent with the critical scores obtained in both "Distress" and "Job domain", and confirms the importance of promoting mental health and the positive morale of operators, as well as their satisfaction with the services they work for.

\section{CONCLUSION}

This survey is limited by the cross-sectional design and the small size of the sample. Furthermore, the use of a questionnaire with a high number of items may invalidate, in this sample, the statistical power of findings. For these reasons, it has to be considered as preliminary and its results need to be confirmed by other studies.

Nevertheless, data pointed out an overall healthy state of the DSM of Lanusei and some correlations between organizational wellbeing dimensions, job satisfaction and psychosomatic symptoms reported by its workers. Thus, the workers who did not report hight levels of psychosomatic symptoms such as nervousness, restlessness, anxiety, headaches/concentration difficulties and sense of depression 
could be more satisfied with the organization, and likely perceive organizational wellbeing.

Many studies [1-5, 7, 11-15, 18, 19] suggest the importance of job satisfation and work engagement among the workers to prevent burnout and job-related distress and to promote organizational wellbeing. Considerating the findings of the present study, we suppose that high level of perceived job satisfation could be related to the "community centred model" in mental health care services. Similar studies should be conducted by including different types of mental health organizations, such as psychiatric hospitals, to explore the differences.

Further studies are required on how workers' job satisfaction and work engagement influence organizational wellbeing, and how these dimensions can be promoted into the mental health organizations.

Finally, this kind of interventional research can be properly implemented among Italian DSMs as a preliminary phase for the work-related distress risk assessment, as expected by Italian low DLgs 81/2008 [23, 25].

\section{CONFLICT OF INTEREST}

The study was partially supported by Funds of the Region of Sardinia (Law n. 7, August 7, 2010, "Promoting scientific research and technology innovation in Sardinia"). All the authors declare they have no conflict of interest.

\section{ACKNOWLEDGEMENTS}

Declared none.

\section{REFERENCES}

[1] Priebe S, Reininghaus U. Fired up, not burnt out - focusing on the rewards of working in psychiatry. Epidemiol Psychiatr Sci 2011; 20: 303-5.

[2] Nelson WA, Taylor E, Walsh T. Building an ethical organizational culture. Health Care Manag (Frederick) 2014; 33(2): 158-64.

[3] Priebe S, Fakhoury W, White I, et al. Assertive Outreach Study Group. Characteristics of teams, staff and patients: associations with outcomes of patients in assertive outreach. Br J Psychiatry 2004; 185: 306-11.

[4] Bakker A, Schaufeli W, Leiter M, Taris T. Work engagement: an emerging concept in occupational health psychology. Work Stress 2008; 22: 187-200.

[5] Gonzalez-Roma V, Schaufeli W, Bakker A, Lloret S. Burnout and engagement: independent factors or opposite poles? J Voc Behav 2006; 68: 165-74.

[6] Avallone F, Paplomatas A. Salute Organizzativa. Milano: Raffaello Cortina Editore 2005.

[7] Carta MG, Kovess V, Hardoy MC, et al. Psychosocial wellbeing and psychiatric care in the European Communities: analysis of macro indicators. Soc Psychiatry Psychiatr Epidemiol 2004; 39(11): 883-92.
[8] Carta MG, Angermeyer MC, Sancassiani F, et al. A follow-up on patients with severe mental disorders in Sardinia after two changes in regional policies: poor resources still correlate with poor outcomes. BMC Psychiatry 2013; 13: 333.

[9] Carta MG, Sancassiani F, Lecca M, et al. Coping with the crisis: people with severe mental disorders acting for social change through sustainable energy. Clin Pract Epidemiol Ment Health 2013; 9: 214-20.

[10] Carta MG. Report della Ricerca "La qualità dell'assistenza in salute mentale nella regione Sardegna: organizzazione e integrazione dei servizi, risposta ai bisogni della popolazione (QAL.SAR.PSY)”. 2013; Regione Autonoma della Sardegna, Assessorato alla Programmazione, Cagliari, Italia

[11] Lasalvia A, Gentile B, Ruggeri M, et al. Heterogeneity of the departments of mental health in the veneto region ten years after the national plan 1994-96 for mental health. Which implication for clinical practice? Findings from the PICOS Project. Epidemiol Psychiatr Soc 2007; 16: 59-70.

[12] Nolan P, Cushway D, Tyler P. A measurement tool for assessing stress among mental health nurses. Nurs Stand 1995; 9: 36-9.

[13] Leiter MP, Harvie PL. Burnout among mental health workers: a review and a research agenda. Int J Soc Psychiatr 1996; 42: 90-101.

[14] Morse G, Salyers MP, Rollins AL, Monroe-DeVita M, Pfahler C. Burnout in mental health services: A review of the problem and its remediation. Adm Policy Ment Health 2012; 39(5): 341-52.

[15] Prosser D, Johnson S, Kuipers E, Szmukler G, Bebbington P, Thornicroft G. Mental health, "burnout" and job satisfaction among hospital and community-based mental health staff. Br J Psychiatry 1996; 169: 334-7.

[16] Thomsen S, Soares J, Nolan P, Dallender J, Arnetz B. Feelings of professional fulfilment and exhaustion in mental health personnel: the importance of organisational and individual factors. Psychother Psychosom 1999; 68: 157-64.

[17] Maslach C, Leiter MP. Early predictors of job burnout and engagement. J Appl Psychol 2008; 98: 498-512.

[18] Kumar S. Burnout and psychiatrists: what do we know and where to from here. Epidemiol Psychiatr Sci 2011; 20: 295-301.

[19] Pisanti R, Paplomatas A, Bertini M. Measuring the positive dimensions among health care workers: a contribution to the Italian validation of the UWES-Utrecht work engagement scale. G Ital Med Lav Ergon 2008; 30(1 Suppl A): A111-9.

[20] Avallone F, Bonaretti M. Benessere organizzativo. Per migliorare la qualità del lavoro nelle amministrazioni pubbliche; Rubettino, Roma 2000.

[21] Fida R, Gualandri M, Avallone F. Organizational wellbeing and psychosocial risk factors in a sample of Italian Public Administration work environments. Med Lav 2011; 102(5): 417-27.

[22] Miglioretti M, Vecchio L, Romano D. Organizational health and quality of service: some remarks from a research among technical and amministrative personnel of the university of Milano-Bicocca. Risorsa Uomo. Rivista di Psicologia del Lavoro e dell'Organizzazione 2009; 15: 4

[23] Persechino B, Valenti A, Ronchetti M, et al. Work-related stress risk assessment in Italy: a methodological proposal adapted to regulatory guidelines. Saf Health Work 2013; 4(2): 95-9

[24] European Agency for Safety and Health at Work. Guidance on work-related stress. Spice of Life or kiss of death? Office for Official Publications of the European Communities, Luxembourg 2000.

[25] Testo Unico sulla Salute e Sicurezza sul Lavoro - D. Lgs 81/2008, Gazzetta Ufficiale n. 101 del 30 aprile 2008 - Suppl. Ordinario n. 108, www.lavoro.gov.it/SicurezzaLavoro 